\title{
Study on Radical Telomerization of Esters of Methacrylic Acid by Using Bromotrichloromethane and Characteristics of the Resulting Telomers II. ${ }^{\dagger}$ Primary Alkyl Methacrylates
}

\author{
Takao KIMURA and Motome HAMASHIMA \\ Department of Environmental Chemistry, Faculty of Engineering, Utsunomiya University, \\ 2753, Ishii-cho, Utsunomiya 321, Japan
}

(Received April 24, 1985)

\begin{abstract}
Radical telomerization of methyl, ethyl, propyl, and butyl methacrylates was carried out by using bromotrichloromethane (BTCM) as a chain transfer agent at 50,70 , and $90^{\circ} \mathrm{C}$. This series of primary alkyl methacrylates showed a similar temperature dependence of the telomerization behavior, but no significant effect of the alkyl chain length of the ester group was observed in the telomerization. The $n$ [Monomer] : [BTCM] adducts, that is, the $n$-mers $(n=1-3)$, were separated by silica gel column chromatography. The increase of the molecular flexibility by increasing the alkyl chain length of the ester group caused a decrease of the melting point in the homologous telomers. The stereochemistry and the reactivity of the homologous telomers were studied by comparing the ${ }^{-1} \mathrm{H}$ NMR spectra and the reactions of dimers. The elimination reaction of dimers with triethylamine gave both two isomeric unsaturated compounds and two isomeric lactones. Heating of dimers in the absence of solvent resulted in the lactonization selectively, and a similar reaction was also observed by the catalytic action of silica gel. The processes of lactonization of the telomers were mechanistically elucidated.
\end{abstract}

KEY WORDS Radical Telomerization / Primary Alkyl Methacrylates Bromotrichloromethane / Silica Gel Column Chromatography / Telomers / ${ }^{1} \mathrm{H}$ NMR / Diastereoisomer / Tacticity / Lactonization / Effect of Substituent /

Bromotrichloromethane (BTCM) is known to be an excellent radical addition reagent for various olefins and a strong telogen for the radical telomerization of vinyl monomers. ${ }^{1-4}$ However, the separation and the structural analysis of telomers synthesized using BTCM as a telogen have rarely been reported except for some $1: 1$ adducts. $^{2}$

Since the corresponding telomeric molecules have labile substituent groups at both ends, they can be utilized as "reactive oligomers" through the chemical modification of their functional groups. Furthermore, studies on the stereochemistry and the reactivity of the lower

\footnotetext{
+ Part I of this series is ref 5.
}

polymers provide valuable data as model compounds for higher polymers, and detailed analyses of the telomers are available for a molecular design of new polymers.

In the previous paper, ${ }^{5}$ we separated methyl methacrylate (MMA) telomers up to trimers synthesized in the presence of BTCM as the telogen and investigated their structures by ${ }^{1} \mathrm{H}$ NMR spectroscopy and chemical reactions. Syndiotactic (st) diastereoisomers were formed preferentially, and no isotactic (it) trimer was found. The most stable conformations of the $s t$ - and it-dimers were suggested to be zigzag and helical, respectively.

The present study was carried out to elucidate the telomerization behavior of a series of 
primary alkyl methacrylates in the presence of BTCM as the telogen and the characteristics of the resulting telomers. In this article, the stereochemistry and the reactivity of the homologous telomers are compared, and the mechanism of the lactonization of the telomers is discussed.

\section{EXPERIMENTAL}

\section{Measurements}

GPC analysis was carried out with a Hitachi 635 chromatograph (column: Shodex A-803, A-802, and KF-802; eluent: THF; detector: RI monitor). Melting points were measured with a model MP-21 apparatus (Yamato) and uncorrected. IR spectra were obtained by the $\mathrm{KBr}$ method with a Hitachi 295 spectrophotometer. ${ }^{1} \mathrm{H}$ NMR spectra were recorded with a JNM-C-60HL $(60 \mathrm{MHz})$ spectrometer (JEOL) using tetramethylsilane as an internal standard in $\mathrm{CCl}_{4}$. Mass spectra were measured with an M-80 (Hitachi) apparatus using a chemical ionization method [20 eV $(3.2 \times$ $\left.10^{-18} \mathrm{~J}\right)$ ]. Satisfactory patterns were obtained for all isotope peaks resulting from bromine and chlorine atoms in the mass spectra. The spectra corresponding only to ${ }^{79} \mathrm{Br}$ and ${ }^{35} \mathrm{Cl}$ are used in this study.

\section{Materials}

Commercial MMA, ethyl (EMA), and butyl (BMA) methacrylates were purified by a conventional method. ${ }^{6}$ Propyl methacrylate (PMA) was synthesized by esterification of methacrylic acid $(0.5 \mathrm{~mol})$ and propyl alcohol $(0.5 \mathrm{~mol})$ in the presence of conc. sulfuric acid $(0.05 \mathrm{~mol})$ as the catalyst and $p$-benzoquinone $(0.005 \mathrm{~mol})$ as a polymerization inhibitor. After refluxing for $24 \mathrm{~h}$, the reaction mixture was extracted with hexane. The organic layer was washed with an aqueous alkaline solution and then with water, and dried overnight with anhydrous sodium sulfate. PMA was obtained in a $62 \%$ yield by distillation in vacuo; bp $43-$ $44^{\circ} \mathrm{C} \quad\left[\begin{array}{lll}16 \mathrm{mmHg} & (2.13 \mathrm{kPa})] & \text { Commercial }\end{array}\right.$
BTCM was purified by distillation under reduced pressure, and 2,2'-azobisisobutyro nitrile (AIBN) by recrystallization from methanol.

\section{Telomerization Procedure}

Telomerization was carried out at 50, 70, and $90^{\circ} \mathrm{C}$ for 24,8 , and $4 \mathrm{~h}$, respectively, under the conditions of $[\mathrm{BTCM}]_{0} /[\text { Monomer }]_{0}=8$ and $[\mathrm{AIBN}]_{0}^{0.5} /[\text { Monomer }]_{0}=0.5$. The reaction mixture was treated in a manner similar to the case of the previous paper. ${ }^{5}$

\section{Separation and Identification of Telomers}

The $n$-mers $(n=1-3)$ were separated by silica gel column chromatography (packing
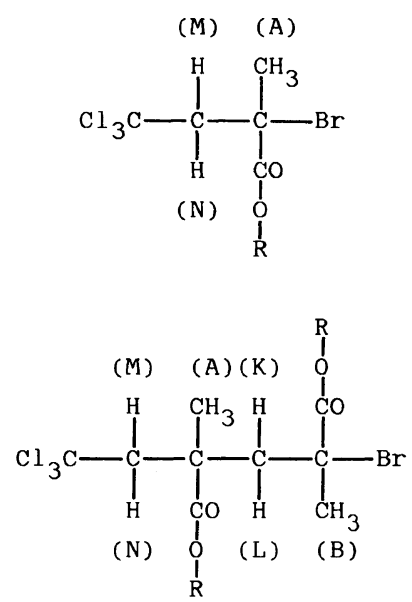

2a

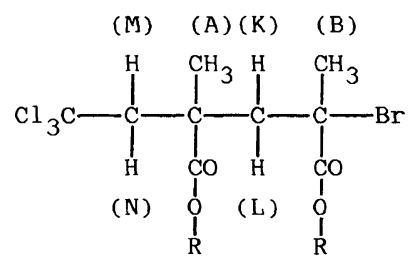

$2 \mathbf{b}$

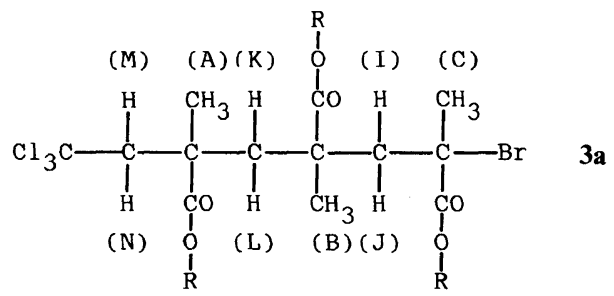


material, Wakogel C-300; eluent, benzene). Separation was achieved rapidly by pressing with nitrogen gas to avoid any side reactions such as lactonization in the column. The eluting order of the telomers was as follows: 1-mer (1) $>$ st-dimer $\quad$ (2a) $>$ it-dimer $\quad$ (2b) $>$ st-trimer (3a). Strongly adsorbed components containing lactones and oligomers higher than trimer were desorbed with methanol.

Identification of the series of telomers and lactones was carried out by a technique similar to the case of previous paper. ${ }^{5}$

\section{Reactions of Telomers}

Elimination Reaction by Triethylamine (TEA). A mixture of a telomer sample and TEA $(1 \mathrm{~g}$ in $10 \mathrm{ml})$ was refluxed for a prescribed time. The reaction mixture was treated in a manner similar to the case of previous paper. $^{5}$

Pyrolysis. A telomer sample was directly heated at a given temperature for a given time in a sealed tube. The lactone yield was determined from ${ }^{1} \mathrm{H}$ NMR data, and if necessary, the product was separated by silica gel column chromatography with benzene.

Catalytic Reaction by Silica Gel. To a solution of a telomer sample $(0.3 \mathrm{~g}$ in $9 \mathrm{ml}$ dry benzene), $3 \mathrm{~g}$ of silica gel (Wakogel C-300, dried at $180-200^{\circ} \mathrm{C}$ for $3 \mathrm{~h}$ ) was added, and the suspended mixture was stirred at $30^{\circ} \mathrm{C}$ for a prescribed time. After the mixture was filtered, the residue was extracted with methanol. The combined filtrate and extract were evaporated to give products. The lactone yield was determined as above.

Hydrolysis. A dimeric telomer was hydrolyzed, under given conditions, to yield the following products: carboxylic acid (8a), $\mathrm{mp}$ $177-179^{\circ} \mathrm{C}$ (dec.); IR $3000(\mathrm{OH})$ and 1780 , $1720 \mathrm{~cm}^{-1}(\mathrm{C}=\mathrm{O})$; mass spectrum $\mathrm{m} / z 289$ $\left(\mathrm{QM}^{+}\right) ;{ }^{1} \mathrm{H}$ NMR (DMSO- $\left.d_{6}\right) \delta 1.30(3 \mathrm{H}, \mathrm{s}$, $\left.-\mathrm{CH}_{3}\right), 1.62\left(3 \mathrm{H}, \mathrm{s},-\mathrm{CH}_{3}\right), 2.72(2 \mathrm{H}, \mathrm{s}$, $\left.-\mathrm{CH}_{2}-\right), 3.13\left(1 \mathrm{H}, \mathrm{d}, \mathrm{J}=15.0 \mathrm{~Hz},-\mathrm{CH}_{2}-\right)$ and $3.48 \mathrm{ppm}\left(1 \mathrm{H}, \mathrm{d},-\mathrm{CH}_{2}-\right)$, and carboxylic acid (8b), mp 116-119 $\mathrm{C}$ (dec.); IR $3150(\mathrm{OH})$ and
$1770,1740 \mathrm{~cm}^{-1}(\mathrm{C}=\mathrm{O})$; mass spectrum $\mathrm{m} / \mathrm{z}$ $289\left(\mathrm{QM}^{+}\right) ;{ }^{1} \mathrm{H}$ NMR $\left(\mathrm{CCl}_{4}\right) \delta 1.58(3 \mathrm{H}, \mathrm{s}$, $\left.-\mathrm{CH}_{3}\right), 1.73\left(3 \mathrm{H}, \mathrm{s},-\mathrm{CH}_{3}\right), 2.19(1 \mathrm{H}, \mathrm{d}$, $\left.J=15.0 \mathrm{~Hz},-\mathrm{CH}_{2}-\right), 3.22\left(2 \mathrm{H}, \mathrm{s},-\mathrm{CH}_{2}-\right), 3.33$ $\left(1 \mathrm{H}, \mathrm{d},-\mathrm{CH}_{2}-\right)$, and $9.03 \mathrm{ppm}(1 \mathrm{H}, \mathrm{s}$, $-\mathrm{COOH})$.

\section{RESULTS AND DISCUSSION}

\section{Telomerization of Primary Alkyl Methacrylates with BTCM}

The results of radical telomerization of a series of primary alkyl methacrylates are summarized in Table I. Figure 1 shows typical GPC diagrams of the products obtained in the telomerization of EMA. Similar chromatograms were also observed in the telomerization of the other monomers. The telomerization of all monomers showed similar temperature dependence of the apparent rate of polymerization $\left(R_{\mathrm{p}}{ }^{\prime}\right)$ and the product distribution (MWD). Above $70^{\circ} \mathrm{C}$, all components of $n \geqq 2$ contained small amounts of lactones in addition to major telomers, and the formation of the lactones increased with increasing reaction temperature. This fact was also confirmed by IR spectra of the whole products as shown in Figure 2. The effect of the alkyl chain length of the ester group was not observed with respect to $R_{\mathrm{p}}{ }^{\prime}$ and MWD. Furthermore, no significant temperature dependence of the tacticity of the dimers was observed except for MMA, and the product ratio of $\mathbf{2 a}$ to $\mathbf{2} \mathbf{b}$ was roughly $4: 1$.

\section{Identification of Telomers and Lactones}

The characterizations of the homologous telomers and lactones are listed in Tables II and III, respectively. The ion peaks based on an identical fragmentation pattern were detected in the mass spectra of the homologous telomers; particularly, the $\alpha$-cleavage of ester groups and the cleavage between bromine and carbon atoms were preferentially occurred.

The ${ }^{1} \mathrm{H}$ NMR parameters of the homologues are summarized in Tables IV and V. 
Table I. Radical telomerization of primary alkyl methacrylates

\begin{tabular}{|c|c|c|c|c|c|c|c|}
\hline \multirow{2}{*}{ Monomer } & \multirow{2}{*}{$\frac{\text { Temp }}{{ }^{\circ} \mathrm{C}}$} & \multirow{2}{*}{$\frac{R_{\mathrm{p}}{ }^{\prime} \times 10^{6}}{\mathrm{moll}^{-1} \mathrm{~s}^{-1}}$} & \multicolumn{3}{|c|}{$\mathrm{MWD} / \mathrm{wt} \%$} & \multicolumn{2}{|c|}{ Tacticity of dimer $/ \%$} \\
\hline & & & $n=1$ & $n=2^{\mathrm{a}}$ & $n \geqq 3$ & $2 a$ & $\mathbf{2 b}$ \\
\hline \multirow{3}{*}{ MMA } & 50 & 8 & 6 & $13[0]$ & 81 & 85 & 15 \\
\hline & 70 & 79 & 22 & $26[2]$ & 52 & 78 & 22 \\
\hline & 90 & 147 & 29 & $30[3]$ & 41 & 75 & 25 \\
\hline \multirow{3}{*}{ EMA } & 50 & 8 & 6 & $16[0]$ & 78 & 83 & 17 \\
\hline & 70 & 70 & 23 & $30[4]$ & 47 & 83 & 17 \\
\hline & 90 & 147 & 33 & $28[5]$ & 39 & 86 & 14 \\
\hline \multirow{3}{*}{ PMA } & 50 & 18 & 13 & $23[0]$ & 64 & 82 & 18 \\
\hline & 70 & 67 & 27 & $28[2]$ & 45 & 82 & 18 \\
\hline & 90 & 140 & 29 & $27[6]$ & 44 & 79 & 21 \\
\hline \multirow{3}{*}{ BMA } & 50 & 15 & 10 & $21[0]$ & 69 & 75 & 25 \\
\hline & 70 & 68 & 25 & 27 [2] & 48 & 85 & 15 \\
\hline & 90 & 138 & 32 & 28 [6] & 40 & 81 & 19 \\
\hline
\end{tabular}

a [ ], the content of dimeric lactones.

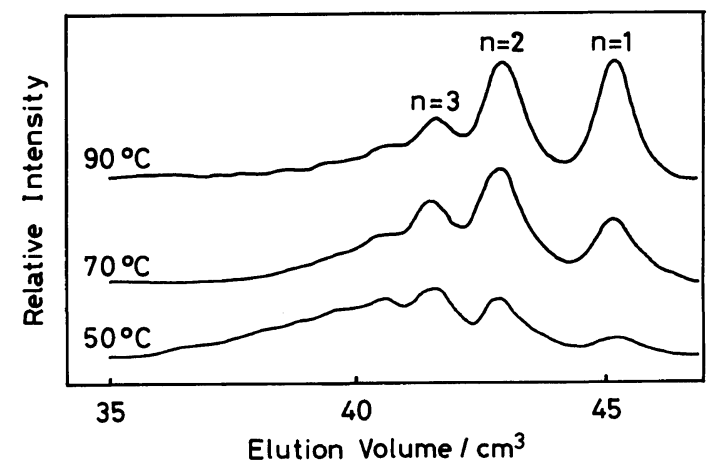

Figure 1. GPC diagrams of the products obtained in the telomerization of EMA.

Methyl- and methylene-proton signals indicated by the same symbol gave nearly identical $\delta$-values regardless of the alkyl chain length of the ester group. All methylene protons of the homologous telomers except for the central methylene protons $(\mathrm{K}, \mathrm{L})$ of $\mathbf{3 a}$ exhibited an AB pattern (doublet-doublet) due to the magnetic nonequivalence. The order of magnitude of the magnetic nonequivalence was as follows: $(\mathrm{M}, \mathrm{N})$ of all $>(\mathrm{K}, \mathrm{L})$ of $\mathbf{2 b}>(\mathrm{K}, \mathrm{L})$ of $\mathbf{2 a} \geqq(\mathrm{I}, \mathrm{J})$ of $\mathbf{3 a}$. The two dimeric lactones (6a) and (6b) showed significantly different $\delta$-values

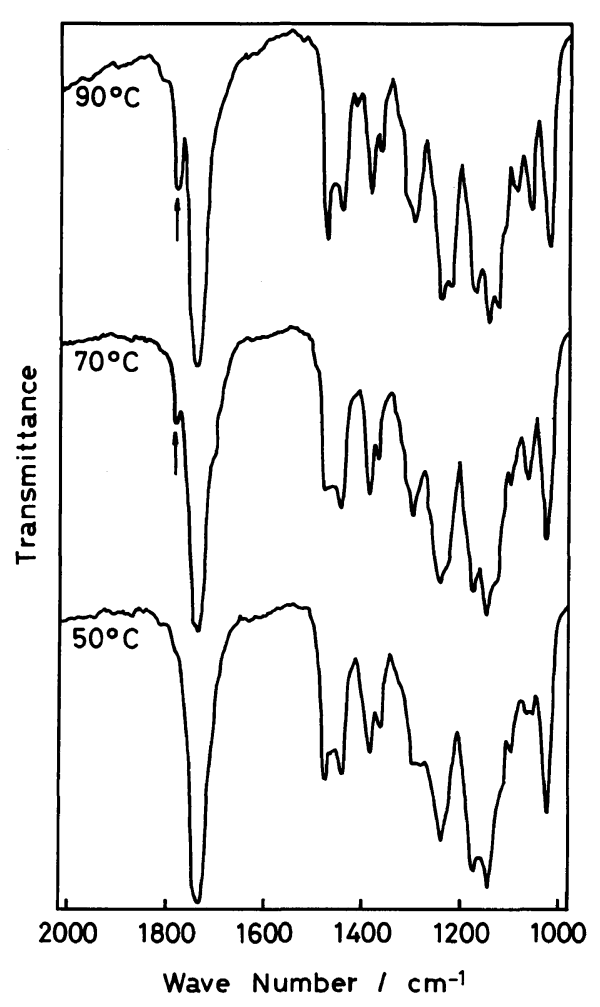

Figure 2. IR spectra of the products whose MWD are illustrated in Figure 1. The arrows show the $\mathrm{C}=\mathrm{O}$ stretching vibration of the lactone ring. 
Telomerization of Alkyl Methacrylates by BTCM

Table II. Characterization of telomers

\begin{tabular}{|c|c|c|c|c|c|}
\hline \multirow{2}{*}{ Telomer } & \multirow{2}{*}{$\mathrm{R}$} & \multirow{2}{*}{ Shape $^{a}$} & $\mathrm{mp}[\mathrm{bp}]$ & \multirow{2}{*}{$\frac{v(\mathrm{C}=\mathrm{O})}{\mathrm{cm}^{-1}}$} & \multirow{2}{*}{$m / z\left(\mathrm{QM}^{+}\right)$} \\
\hline & & & ${ }^{\circ} \mathrm{C}$ & & \\
\hline \multirow{4}{*}{1} & $\mathrm{Me}$ & $\mathrm{C}$ & {$[111-113 / 8 \mathrm{mmHg}]$} & 1750 & 297 \\
\hline & Et & $\mathrm{C}$ & {$[77-78 / 1 \mathrm{mmHg}]$} & 1745 & 311 \\
\hline & $n-\operatorname{Pr}$ & $\mathrm{C}$ & {$[114-116 / 4 \mathrm{mmHg}]$} & 1745 & 325 \\
\hline & $n-\mathrm{Bu}$ & $\mathrm{C}$ & {$[105-106 / 2 \mathrm{mmHg}]$} & 1745 & 339 \\
\hline \multirow{4}{*}{$\mathbf{2 a}$} & $\mathrm{Me}$ & A & $58-59.5$ & 1735 & 397 \\
\hline & Et & A & $48-49$ & 1740 & 425 \\
\hline & $n-\operatorname{Pr}$ & A & $23-25$ & 1730 & 453 \\
\hline & $n-\mathrm{Bu}$ & B & $-^{\mathrm{b}}$ & 1740 & 481 \\
\hline \multirow{4}{*}{$\mathbf{2 b}$} & $\mathrm{Me}$ & A & $79-80$ & 1730 & 397 \\
\hline & Et & A & $17.5-19$ & 1735 & 425 \\
\hline & $n-\operatorname{Pr}$ & B & - $^{\mathrm{b}}$ & 1740 & 453 \\
\hline & $n-\mathrm{Bu}$ & B & $-^{\mathrm{b}}$ & 1740 & 481 \\
\hline \multirow{4}{*}{ 3a } & $\mathrm{Me}$ & A & $111-112$ & 1735 & 497 \\
\hline & Et & A & $62.5-64.5$ & 1725 & 539 \\
\hline & $n-\operatorname{Pr}$ & B & - $^{\mathrm{b}}$ & 1730 & - \\
\hline & $n-\mathrm{Bu}$ & B & $-^{\mathrm{b}}$ & 1740 & - \\
\hline
\end{tabular}

a A, colorless crystals; B, colorless viscous oil; C, colorless liquid.

b Not solidified at $-10^{\circ} \mathrm{C}$.

Table III. Characterization of lactones

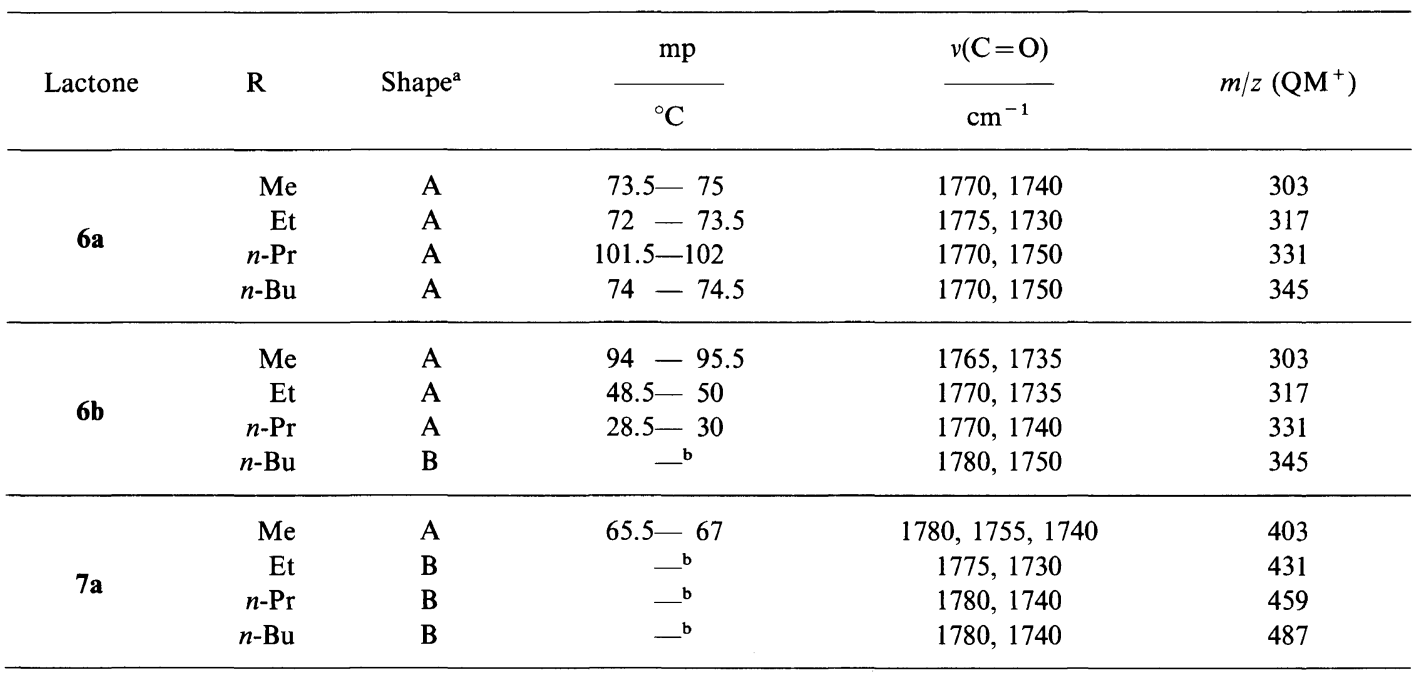

a A, colorless crystals; B, colorless viscous oil.

b Not solidified at $-10^{\circ} \mathrm{C}$.

of methylene protons $(\mathrm{K}, \mathrm{L})$ and $(\mathrm{M}, \mathrm{N})$, and figuration as discussed in the previous paper. ${ }^{5}$ this may be explained by the difference in the The proton signals of the ester groups, which magnetic environment based on a stable con- are omitted in the tables, appeared in expected 
Table IV. ${ }^{1} \mathrm{H}$ NMR parameters of telomers

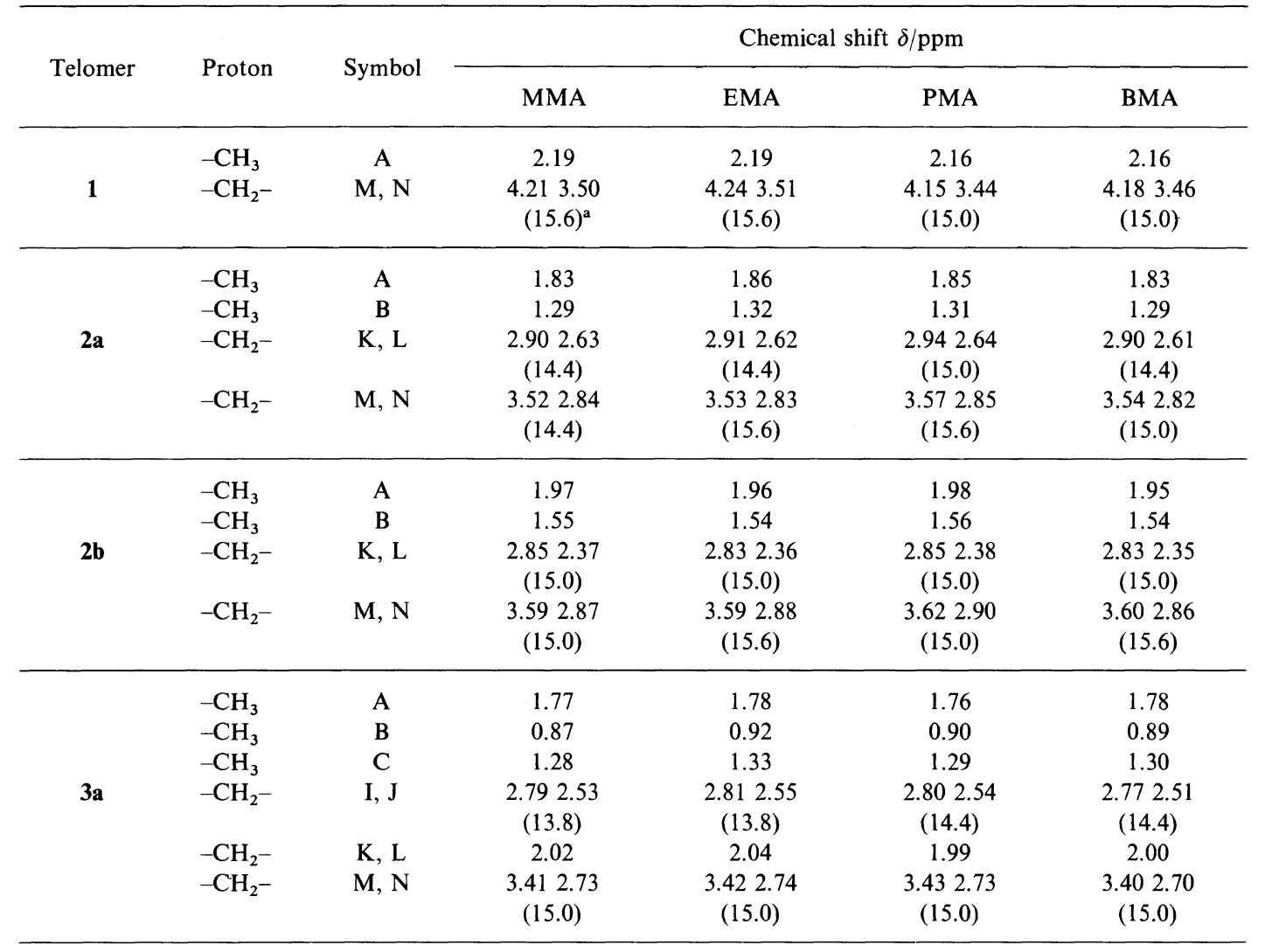

a ( ), coupling const. $J$ in $\mathrm{Hz}$.

resonance regions.

\section{Reactivity of Telomers}

Elimination Reaction by TEA. The reaction of 1 with TEA was found to proceed following Saytzeff's law, and the elimination product (4) was exclusively obtained after $20 \mathrm{~h}$ in the following yields: MMA, $83 \%$; EMA, 64\%; PMA, $79 \%$; and BMA, $81 \%$. However, the law was not followed in similar reactions of dimers as shown in Table VI, and all dimers, except $\mathbf{2 b}$ $(\mathrm{R}=\mathrm{Me})$, gave the terminally unsaturated compound (5a) in preference to the internally unsaturated compound (5b). Furthermore, two dimeric lactones $\mathbf{6 a}$ and $\mathbf{6 b}$ were also obtained in the reaction of dimers with TEA. The proportion of the two lactones in the products increased with the alkyl chain length of the ester groups, as opposed to that of the two unsaturated compounds. But no significant effects of the alkyl substituent groups were observed on the ratio of the isomeric products.

Pyrolysis. Heating of dimers in the absence of solvent resulted in the lactonization easily, and the reaction proceeded by the following routes: $\mathbf{2 a} \rightarrow \mathbf{6 a}$ and $\mathbf{2 b} \rightarrow \mathbf{6 b}$. Figure 3 shows the time-conversion plots of the lactonization of 2a $(\mathrm{R}=\mathrm{Et})$. The reaction was completed in about $12 \mathrm{~h}$ at $100^{\circ} \mathrm{C}$, and in about $1 \mathrm{~h}$ at $150^{\circ} \mathrm{C}$. On heating at $150^{\circ} \mathrm{C}$ for $5 \mathrm{~min}(10 \mathrm{~min})$, dimers 2a gave 6a in the following yields: MMA, 49\% $(70 \%)$; EMA, 50\% (74\%); PMA, $48 \%(73 \%)$; and BMA, $49 \%(61 \%)$. The effects of the alkyl 
Telomerization of Alkyl Methacrylates by BTCM

Table V. ${ }^{1} \mathrm{H}$ NMR parameters of lactones

\begin{tabular}{|c|c|c|c|c|c|c|}
\hline \multirow{2}{*}{ Lactone } & \multirow{2}{*}{ Proton } & \multirow{2}{*}{ Symbol } & \multicolumn{4}{|c|}{ Chemical shift $\delta / \mathrm{ppm}$} \\
\hline & & & MMA & EMA & PMA & BMA \\
\hline \multirow{5}{*}{$6 \mathbf{a}$} & $-\mathrm{CH}_{3}$ & A & 1.67 & 1.66 & 1.65 & 1.65 \\
\hline & $-\mathrm{CH}_{3}$ & B & 1.32 & 1.32 & 1.30 & 1.30 \\
\hline & $-\mathrm{CH}_{2-}^{-}$ & $\mathrm{K}, \mathrm{L}$ & 2.75 & 2.73 & 2.73 & 2.73 \\
\hline & $-\mathrm{CH}_{2}-$ & $\mathrm{M}, \mathrm{N}$ & 3.383 .07 & 3.363 .05 & 3.363 .06 & 3.353 .05 \\
\hline & & & $(16.2)^{\mathrm{a}}$ & $(16.2)$ & $(16.2)$ & $(15.6)$ \\
\hline \multirow{5}{*}{$\mathbf{6 b}$} & $-\mathrm{CH}_{3}$ & A & 1.66 & 1.67 & 1.69 & 1.66 \\
\hline & $-\mathrm{CH}_{3}$ & B & 1.53 & 1.55 & 1.57 & 1.55 \\
\hline & $-\mathrm{CH}_{2}-$ & $\mathrm{K}, \mathrm{L}$ & 3.242 .08 & 3.282 .06 & 3.282 .07 & 3.262 .03 \\
\hline & & & $(14.4)$ & $(14.4)$ & (14.4) & $(14.4)$ \\
\hline & $-\mathrm{CH}_{2-}$ & $\mathrm{M}, \mathrm{N}$ & 3.18 & 3.19 & 3.20 & 3.18 \\
\hline \multirow{8}{*}{$7 \mathbf{a}$} & $-\mathrm{CH}_{3}$ & A & 1.59 & 1.59 & 1.60 & 1.62 \\
\hline & $-\mathrm{CH}_{3}$ & $\mathrm{~B}$ & 1.59 & 1.59 & 1.60 & 1.62 \\
\hline & $-\mathrm{CH}_{3}$ & $\mathrm{C}$ & 1.17 & 1.20 & 1.19 & 1.20 \\
\hline & $-\mathrm{CH}_{2}-$ & $\mathrm{I}, \mathrm{J}$ & 1.90 & 1.91 & 1.91 & 1.93 \\
\hline & $-\mathrm{CH}_{2}-$ & $\mathrm{K}, \mathrm{L}$ & 2.442 .14 & 2.452 .17 & 2.472 .18 & 2.482 .18 \\
\hline & & & (13.8) & (13.2) & (13.8) & (13.8) \\
\hline & $-\mathrm{CH}_{2}-$ & $\mathrm{M}, \mathrm{N}$ & 3.672 .84 & 3.692 .86 & 3.712 .87 & 3.762 .90 \\
\hline & & & $(15.0)$ & $(15.0)$ & (15.6) & $(15.0)$ \\
\hline
\end{tabular}

a ( ), coupling const. $J$ in $\mathrm{Hz}$.

Table VI. Elimination of dimers with TEA ${ }^{\mathrm{a}}$

\begin{tabular}{|c|c|c|c|c|c|c|}
\hline \multirow{2}{*}{ Dimer } & \multirow{2}{*}{$\mathrm{R}$} & \multicolumn{4}{|c|}{ Yield of products $/ \%$} & \multirow{2}{*}{$\frac{\text { Recovd. }}{\%}$} \\
\hline & & $5 \mathbf{a}$ & $5 \mathbf{b}$ & $6 \mathbf{a}$ & $\mathbf{6 b}$ & \\
\hline \multirow{4}{*}{$2 \mathbf{a}$} & $\mathrm{Me}$ & 44 & - & - & 22 & - \\
\hline & Et & 40 & - & 15 & 5 & 30 \\
\hline & $n-\operatorname{Pr}$ & 25 & - & 27 & 31 & - \\
\hline & $n-\mathrm{Bu}$ & 18 & - & 23 & 23 & 9 \\
\hline \multirow{4}{*}{ 2b } & $\mathrm{Me}$ & 13 & 24 & - & 26 & - \\
\hline & Et & 31 & - & - & 11 & 45 \\
\hline & $n-\operatorname{Pr}$ & 15 & 7 & 13 & 26 & 2 \\
\hline & $n-\mathrm{Bu}$ & 9 & 6 & 14 & 33 & 10 \\
\hline
\end{tabular}

a Reaction time, $60 \mathrm{~h}$.

substituent groups were not observed on the lactone yields. Similarly, 3a gave trimeric lactone (7a) exclusively by heating at $200^{\circ} \mathrm{C}$ for $2 \mathrm{~h}$.

Catalytic Reaction by Silica Gel. The lactonization was also observed in the catalytic action of silica gel, and the reaction proceeded

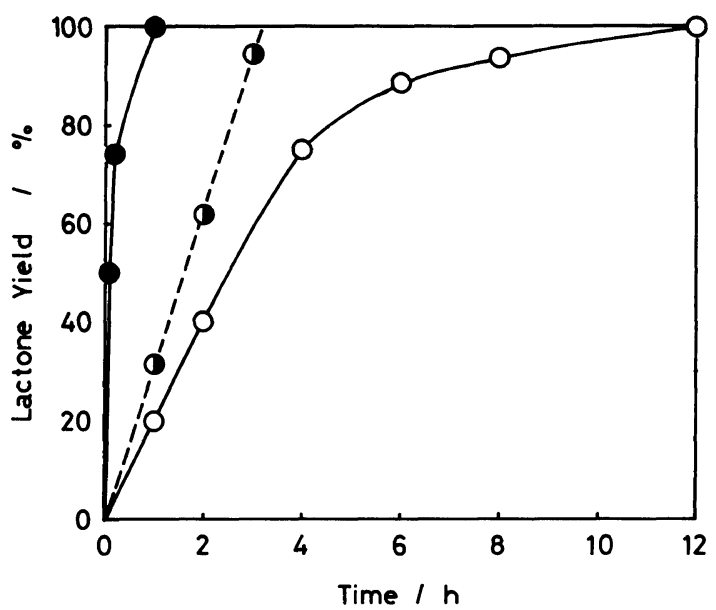

Figure 3. Time-conversion plots of the lactonization in pyrolysis: Sample, $50 \mathrm{mg}$ of $2 \mathrm{a}(\mathrm{R}=\mathrm{Et}) ; \mathrm{O}, 100^{\circ} \mathrm{C}$; $\mathrm{C}$, $100^{\circ} \mathrm{C}$ in the presence of a drop of water;, $150^{\circ} \mathrm{C}$.

by the same route as pyrolysis. The reactivities of $\mathbf{2 a}$ and $\mathbf{2 b}$ were greatly different in this case and the conversion of $\mathbf{2} \mathbf{b}$ was greater than that of $2 \mathbf{a}$. As discussed in the previous paper, ${ }^{5}$ the 


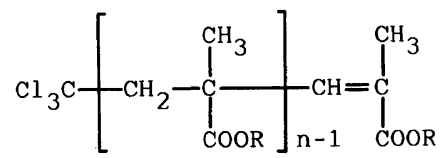

$n=1: 4$

$n=2: 5 b$

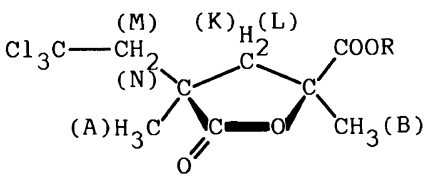

$6 a$<smiles>[R]OC(=O)C(C)(CC)CC(=C)C(=O)O</smiles>

5a

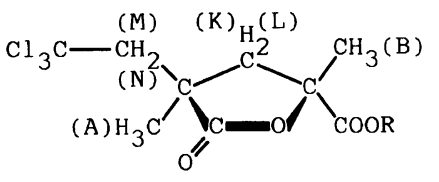

6b<smiles>[R]OC(=O)C(C)(C)C(=O)OC(C)(C)C(=O)CC(C)(CC)C(=O)O</smiles>

$\mathbf{7 a}$

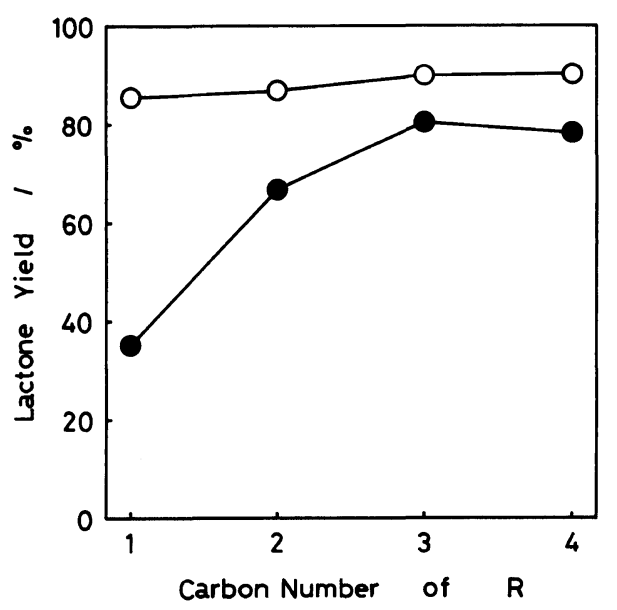

Figure 4. Dependence of carbon number in primary alkyl substituent $(R)$ in the lactonization by silica gel: $O$, 2a (time, $72 \mathrm{~h}$ ); $\mathbf{0}$, $\mathbf{b}$ (time, $4 \mathrm{~h}$ ).

difference in this reactivity of the lactonization is attributable to the configurational differences of $\mathbf{2 a}$ and $\mathbf{2 b}$. Furthermore, the lactoni-

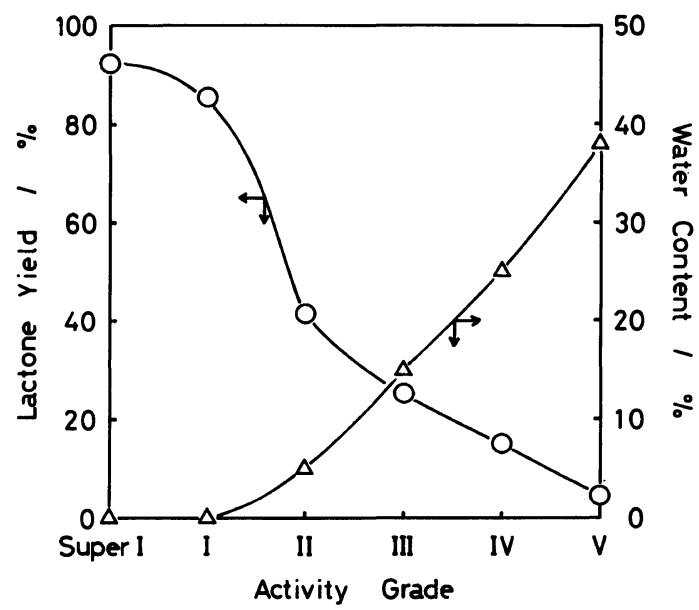

Figure 5. Effect of water content in the lactonization by silica gel: Sample, $2 \mathrm{a}(\mathrm{R}=\mathrm{Me})$; time, $72 \mathrm{~h}$.

zation of dimers by silica gel generally increased with an increase in the alkyl chain length of the ester groups as shown in Figure 4. Under similar conditions to those in the case 


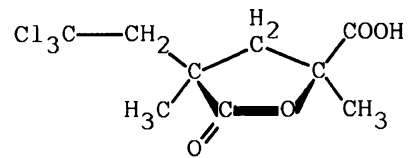

$8 \mathbf{a}$<smiles>CCC1(C)CC(C)(C(=O)O)OC1=O</smiles>

8b
Table VII. Hydrolysis of dimers with typical acid- and base-catalysts

\begin{tabular}{|c|c|c|c|c|c|}
\hline \multirow{2}{*}{ Dimer } & \multirow{2}{*}{ Condition $^{\mathrm{a}}$} & \multicolumn{4}{|c|}{ Yield of products $/ \%$} \\
\hline & & $6 a$ & $\mathbf{6 b}$ & $\mathbf{8 a}$ & $\mathbf{8 b}$ \\
\hline \multirow[t]{2}{*}{$2 \mathrm{a}(\mathrm{R}=\mathrm{Me})$} & i) & 14 & - & 84 & - \\
\hline & ii) & - & - & - & 82 \\
\hline \multirow[t]{2}{*}{$\mathbf{2 b}(\mathrm{R}=\mathrm{Me})$} & i) & - & 14 & - & 67 \\
\hline & ii) & - & - & 59 & - \\
\hline
\end{tabular}

a i), a solution of dimer $(1 \mathrm{~g})$ in conc. $\mathrm{H}_{2} \mathrm{SO}_{4}(6 \mathrm{ml})$ was stirred at $40^{\circ} \mathrm{C}$ for $24 \mathrm{~h}$; ii), a solution of dimer $(1 \mathrm{~g})$ in $10 \% \mathrm{KOH}-\mathrm{MeOH}: \mathrm{H}_{2} \mathrm{O}[9: 1](6 \mathrm{ml})$ was stirred at $40^{\circ} \mathrm{C}$ for $24 \mathrm{~h}$.

of $\mathbf{2 a}$, trimer $\mathbf{3 a}$ was converted to $\mathbf{7 a}$ in the following yields: MMA, 44\%; EMA, 69\%; PMA, $51 \%$; and BMA, $57 \%$.

\section{Mechanistic Consideration of Lactonization}

The lactonization of $\mathbf{2 a}(\mathrm{R}=\mathrm{Et})$ by heating at $100^{\circ} \mathrm{C}$ was accelerated by the addition of water as shown in Figure 3, and the lactonization was also observed in the presence of an equimolar amount of 1,1-diphenyl-2-picrylhydrazyl as radical scavenger. Furthermore, ethyl bromide was simultaneously detected as an elimination product, which was identified with an authentic sample by ${ }^{1} \mathrm{H}$ NMR.

The behavior in lactonization of $\mathbf{2 a}$ $(\mathrm{R}=\mathrm{Me})$ by silica gel varied greatly with the activity of silica gel as shown in Figure 5. The activity of silica gel was adjusted by the addition of water in accordance with Activity Grade of Brockmann. ${ }^{7}$ The silica gel dried at $180-200^{\circ} \mathrm{C}$ for $3 \mathrm{~h}$ corresponds to Activity Grade I. The yield of lactone decreased with an increase in the water content in the silica<smiles>[R]OC(C)(CC([R])([R])Br)CC(C)(C)Br</smiles><smiles>[R]OC(C)(CCC([R])(C)Br)C([R7])Br</smiles>

III

$\begin{array}{ll}\text { 2a: }: \mathrm{R}_{1}=\mathrm{CH}_{3}, \mathrm{R}_{2}=\mathrm{COOR}^{\prime \prime} & \mathbf{2 a} \\ \text { 2b: } \mathrm{R}_{1}=\mathrm{COOR}, \mathrm{R}_{2}=\mathrm{CH}_{3} & \mathbf{2 b}\end{array}$

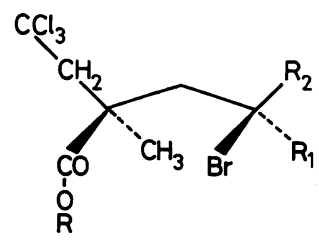<smiles>[R]O[C@](C)(CC([R7])([R7])Br)CC([R])([3H])Br</smiles>

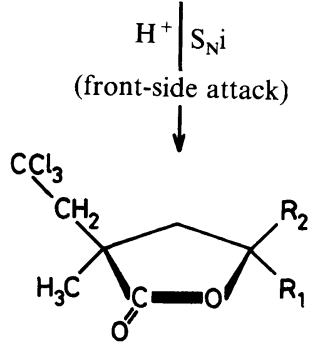

6a: $\mathrm{R}_{1}=\mathrm{CH}_{3}, \mathrm{R}_{2}=\mathrm{COOR}$ 6b: $\mathrm{R}_{1}=\mathrm{COOR}, \mathrm{R}_{2}=\mathrm{CH}_{3}$

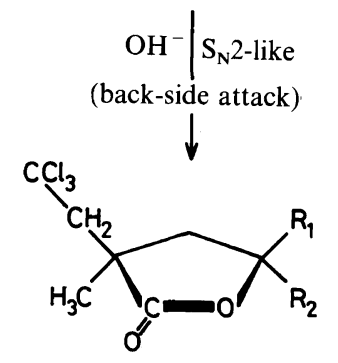

$8 b: R_{1}=\mathrm{CH}_{3}, \mathrm{R}_{2}=\mathrm{COOH}$ 8a: $\mathrm{R}_{1}=\mathrm{COOH}, \mathrm{R}_{2}=\mathrm{CH}_{3}$

Scheme 1. Mechanisms of lactonization.

gel. When the physically adsorbed water was thoroughly removed from the silica gel, the catalytic ability was found to reach a maximum. Similar lactonization reactions also took place by the action of a typical proton donor, conc. sulfuric acid, as shown in Table VII. Therefore, the lactonization of telomers with silica gel is considered to be promoted by a Brønsted acid such as silanol attached to the surface of the catalyst.

On the other hand, in the lactonization of dimers by TEA, no selectivity of the two isomers $6 \mathbf{a}$ and $\mathbf{6 b}$ was observed. The following 
lactonization reactions, $2 \mathrm{a} \quad(\mathrm{R}=\mathrm{Me}) \rightarrow$ carboxylic acid $(\mathbf{8 b})$ and $\mathbf{2 b}(\mathrm{R}=\mathrm{Me}) \rightarrow$ carboxylic acid (8a), took place by the action of a typical base, $10 \%$ aqueous potassium hydroxide, as shown in Table VII.

The lactonization in pyrolysis and in the presence of silica gel is considered to take place through a cationic $S_{N}$ i mechanism, and the lactonization with a base-catalyst, a $\mathrm{S}_{\mathrm{N}} 2$-like mechanism as shown in Scheme 1.

Acknowledgments. The authors are grateful to Mr. T. Ichikawa, Mr. H. Katō, and Mr. M. Tamura for their help in this study.

\section{REFERENCES}

1. T. Sasaki, T. Migita, K. Izawa, and H. Tomioka, "Fukahannō (Addition Reactions)," Maruzen Co., Tokyo, 1975, pp 235-300.

2. M. S. Kharasch, O. Reinmuth, and W. H. Urry, $J$. Am. Chem. Soc., 69, 1105 (1947).

3. C. A. Barson, R. R. Mather, and J. C. Robb, Trans. Farady Soc., 66, 2585 (1970).

4. C. A. Barson, A. R. Luxton, and J. C. Robb, J. Chem. Soc., Faraday Trans. 1, 68, 1666 (1972).

5. T. Kimura, T. Kodaira, and M. Hamashima, Polym. J., 15, 293 (1983).

6. T. Otsu and M. Kinoshita, "Kobunshi Gosei no Jikkenhō (Experimental Methods of Polymer Synthesis)," Kagaku Dōjin Co., Kyoto, 1976, pp $74-75$.

7. T. Tsuyuki and R. Aoyagi in "Shin Jikken Kagaku Koza (Lecture of New Experimental Chemistry)," Vol. 1 (I), The Chemical Society of Japan, Ed., Maruzen Co., Tokyo, 1975, Section 4.4. 